\title{
The Influence of Work-Family Interface and Emotional Exhaustion on Turnover Intention Among Doctors in Malaysian Public Hospitals: Applying Affective Commitment as the Moderator
}

\author{
Ifrah Harun ${ }^{1, *}$ Rosli Mahmood ${ }^{2}$ \\ 1,2 Putra Business School, Universiti Putra Malaysia, Serdang, Selangor, Malaysia \\ *Corresponding author. Email: ifrahharun@gmail.com
}

\begin{abstract}
Drawing from a Job-Demand and Resource (J-DR) model and Conservation of Resources theory (COR), this study aims to examine the moderating role of affective commitment in relation to work-family interface (WFI), emotional exhaustion(EE), and turnover intention. Particularly, this study examines how the influence of affective commitment contribute in buffering the impact of WFI [which includes work-family conflict (WFC) and family-work conflict(FWC)] on emotional exhaustion and turnover intention. Data were collected from 202 medical doctors from various clinical departments across four Malaysian public hospitals. A self-report survey was administered to clinical doctors, excluding those in management, research, and training institutions. Partial Least Square-Structural Equation Modelling (PLS-SEM) version 3.2.8 was employed for data analysis. As hypothesised, WFI (WFC/FWC) and emotional exhaustion are positively associated with turnover intentions. The findings also revealed that emotional exhaustion increased when WFC was amplified but not FWC and that this relationship was stronger when affective commitment was low and weaker when it was high. The empirical study revealed that affective commitment may be considered as protective resources for doctors. Furthermore, the results showed that high work-family interface should not have a notable impact when doctors have a high affective commitment thus reducing emotional exhaustion and turnover intentions.
\end{abstract}

Keywords: Affective commitment, emotional exhaustion, turnover intention, work-family interface.

\section{INTRODUCTION}

Turnover among health professionals remains a pertinent concern around the globe owing to its detrimental impact on one's well-being [1]. As outlined in the sustainable development goals (SDG) and millennium development goals (MDG) initiatives, all countries are accountable for providing sufficient and top-quality healthcare workers to cater for the unmet needs of the population [2]. In this sense, a high turnover rate among doctors can become a barrier in achieving SDG and MDG goals. Considering the nature of medical professions, issues such as irregular and hectic working hours, low salary and excessive workload are some of the illustrations of the stressful working conditions [3] [4]. Furthermore, the toxic work environment will also deflate psychological health and even physical well-being. Therefore, inconducive work conditions have been known to directly affect health workers' stress level and well-being as more resources have been devoted to work roles, which trigger conflict between work and family obligations that may lead to the propensity to leave a job. 
The Malaysian healthcare sector as seen in other female-dominated professions is riddled with stressrelated issues at the work and family interface. The national scenario indicated an exponential trend in the number of dual-earners and single-parent households which have sparked an interest to gauge further its impact towards the work and family interface [5]. The present scenario also recorded an increase in Malaysia's ageing population [6] which usually requires the children to take care of their parents, and at the same time juggle strenuous working life and family obligations. This demographic pattern has shifted the interconnection between work and family roles and may trigger a potential imbalance of the work-family interface.

The aim of this paper is three-fold. First, to examine the influence of work-family interface (WFI) on turnover intention. Second, to assess the mediating effect of emotional exhaustion (EE) in relation to work-family interface (WFI) and turnover intention (TI). Lastly, to assess the moderating effects of affective commitment in buffering WFI-TI ties. The novelty of this study lies in the integration of job demands (WFI, EE), personal resources and job outcomes drawing from the COR theory and JD-R model in the Malaysian public healthcare context.

\subsection{Theoretical and Hypothesis Development}

\subsubsection{Conservation of Resources (COR) Theory}

Researchers suggested the COR theory [7] as an underpinning theory in predicting the nexus between WFI and TI. According to the COR theory, employees are encouraged to preserve and gain a pool of resources. When someone is confronted with resource loss, they will experience higher stress. To mitigate this, one needs to protect their remaining resources by reinvesting on other resources to replenish the actual loss of resources. The occurrence of this investment might deplete other resources and eventually become receptive to spiral loss [8]. When one requires to fulfil their work obligations, they tend to sacrifice their family time to accommodate those demands [9].

\subsubsection{Job Demand and Resource (JD-R) Model}

Recent theoretical development known as the JD$\mathrm{R}$ model proposed by esteemed scholars [10] has been used to demonstrate a flexible theoretical approach in underpinning stressors and strain-related research such as job stressors, burnout, engagement, and inter-role conflict. The model encompasses two main components of job characteristics, namely job demands and job resources, that are significantly related and extremely crucial in influencing the wellbeing of the population [11]. The JD-R model consists of two crucial psychological processes, namely, the motivational process and health impairment (stress) process.

\subsubsection{WFI}

WFI refers to a process in which an individual's performance and behaviour in the work or family domain is influenced by various types of resources and pressures generated from the work or family domain [12]. There are two types of WFI, namely, work-family conflict (WFC) and family-work conflict (FWC). WFC relates to the experience gained from work roles that interfere with the family domain whereas FWC occurs when family roles intrude with the work domain. WFI is a vital challenge, given its intense and taxing demand on work conditions, particularly among medical doctors. The nature of a medical personnel's job characteristics tends to impede the balance between work and family responsibilities, hence likely triggering conflict between work and non-work obligations [13][14][15][16].

\subsection{4. $E E$}

Burnout is psychological stress as a result of stressful demand and compulsive exposure to job stressors. This is true as burnout occurs when demands at work surpass available resources [11]. Theoretically, three main components of burnout consist of emotional exhaustion, depersonalisation, and personal accomplishment [17]. Based on stress literature, emotional exhaustion posits as the most significant components compared to the rest, and as such emotional exhaustion has been employed to represent burnout in this study [18]. Under the lens of the COR theory, emotional exhaustion is depicted as resource loss which instigates coping mechanisms that are frequently linked with the intention to quit [19][20][21]. The taxing demands among healthcare professionals signify threats to available resources, producing stress that leads to emotional exhaustion [11][22][23][24].

\subsection{5. $A C$}

Affective commitment, as defined in previous research [25], refers to an individual's attachment to the workplace whereby its strength can differ from 
low to a high levels. When employees are emotionally attached and highly committed to their organisation, it blurring boundaries between their self and current organisation may take place. Optimistic and fully committed staff would produce better performance and job-related outcomes such as high presenteeism [26]. Employees who have a poor association with their organisation tend to succumb to a lack of commitment and negative repercussion of work outcomes [27].

\subsection{6. $T I$}

Turnover from employment has enticed researchers and practitioners attention for over a century, wherein its theories, concepts, and models have evolved since then (1). Given its importance, scholars have lamented that turnover intentions are identified as the influential predictors of actual turnover [28]. Turnover intention refers to a cognizant and deliberate wilfulness to quit a job [29], and also consider leaving as part of a coping mechanism from the COR point of view. Based on the COR theory, turnover intentions are considered an alternative to counter resource threats or resource loss.

\subsubsection{WFI and TI}

Most studies on work-family interface research to date, particularly in Asian settings have only focused on one side of WFC directional relationship rather than bidirectional interactions [30]. One major drawback of this approach is that researchers might neglect the potential effects of both WFI types on job-related outcomes [12]. Meta-analyses studies demonstrated that several studies substantiated positive linkages between WFI and turnover intentions [31]. Notably, employees tend to leave a job and alternatively seek more family-friendly employment to diminish the existence of WFC. In a similar vein, when a person is faced with FWC, employees seem to opt for job quitting as a way to mitigate FWC and fulfil family duties [32]. For example, an employee might give up their work due to overtaxing demands that keep intruding into their family life [33]. As such, the following were hypothesised:

Hypothesis 1(a): WFC is positively related to turnover intention, based on the matching-domain perspective
Hypothesis 1(b): FWC is positively related to turnover intention, based on cross-domain perspective

\subsubsection{WFI, EE and TI}

Studies in the past two decades demonstrated that WFI is related to turnover intentions, burnout, and job satisfaction [34][35][36]. Individuals with high WFI would induce stress as they encountered resource loss due to a growing battle to cope with work and family obligations. Recent studies also indicated the connection between WFI and burnout, specifically emotional exhaustion as a key dimension of burnout [24][26][37].

Drawing from the JD-R model, emotional exhaustion through the health impairment process occurs as a result of disproportion between job demands and job resources. According to this model, WFI is considered as job demands and is presumably related to emotional exhaustion, therefore jeopardising employees' well-being. Therefore, the following were hypothesised:

Hypothesis 2(a): WFC is positively related to emotional exhaustion

Hypothesis 2(b): FWC is positively related to emotional exhaustion

Hypothesis 3(a): Emotional exhaustion mediates the relationship between work-family conflict and turnover intention.

Hypothesis 3(b): Emotional exhaustion mediates the relationship between family-work conflict and turnover intention.

\subsubsection{AC as moderator}

In a recent study [38] it was revealed that the moderating effects of work-family dynamics related to specific leader support which buffered the association between WFC and turnover intentions. Collective affective commitment moderates the linkages between WFC and emotional exhaustion [39].

A decrease in an individual's commitment is associated with work-family conflict. The notion behind this is attributed to affective commitment, which is prone to emotional attachment, selfassurance and feeling a sense of belonging to the organisation. The interaction between affective 
commitment and work-family interface in relation to emotional exhaustion has been insufficiently explored [39]. In this sense, it was assumed that when doctors are highly committed, they tend to psychologically attach to their workplace and adapt well to their organisation. Based on the arguments, it was posited that:

Hypothesis 4(a): Affective commitment moderates the relationship between work-family conflict and turnover intention, such that the intensity of linkages between WFC and TI are high when AC is low

Hypothesis 4(b): Affective commitment moderates the relationship between family-work conflict and turnover intention, such that the intensity of linkages between FWC and TI are high when AC is low

\section{METHOD}

\subsection{Procedures}

The sample consisted of 202 medical doctors (excluding house officers, and those in management, research, and training departments) from four Malaysian public hospitals using self-administered questionnaires. The purpose of the study was presented to the voluntary participants during continuous medical education (CME) sessions. 202 of 500 questionnaires were returned with a response rate of 40.4 per cent. Ethics approval was obtained from the Medical Research and Ethics Committee, National Medical Research Register, Ministry of Health Malaysia (NMRR-19-1028-47848 (IIR).

\subsection{Measures}

Work-family interface (WFC and FWC) was quantified using six items from [40] with a sevenpoint scale from 7 (strongly agree) to 1 (strongly disagree) range. The Cronbach's $\alpha$ values reported in the current study was 0.875 (WFC) and 0.904 (FWC) respectively. Emotional exhaustion was measured using the nine-item emotional exhaustion scale as part of the Maslach Burnout Inventory (18). A sixpoint scale $(0=$ never, and $6=$ everyday $)$ was utilised in this scale. The Cronbach's $\alpha$ values for the scale was 0.725 . Affective commitment was evaluated using the affective commitment scale by previous research [41] with a seven-point scale ranging from 7 (strongly agree) to 1 (strongly disagree). In the current study, the Cronbach's $\alpha$ values for the scale was 0.872. Turnover intention was examined using six items from turnover intentions scale by a previous study [42] based on a seven-point scale. In the present study, the Cronbach's $\alpha$ value of this scale was 0.867 .

\subsection{Data Analysis}

SPSS was used to examine descriptive analysis while SmartPLS version 3.2.8 was employed to assess the measurement and structural model in this study. The advantage of this technique is that it analyses non normally distributed data since normality assumption is not required [43]. This statistical tool was chosen because most common survey research is usually not normally distributed [44]. Given that the data was gathered from a single source, the common method bias was assessed by testing full collinearity as seen in a previous study [45]. All variables were then regressed against a common variable and bias would not be an issue if the VIF value $\leq 3.3$ (range from 1.029 to 1.644 ). In this study, the results produced VIF less than 3.3, thus single-source bias was not a critical concern in the collected data.

\section{RESULTS}

\subsection{Measurement model}

To examine the measurement model, a two-step approach was selected as suggested by an earlier study [46]. The first steps were to evaluate the measurement model by testing the reliability and validity of the instruments [47]. The loadings, average variance extracted (AVE) and the composite reliability $(\mathrm{CR})$ for the measurement model were examined. The threshold values of loadings and AVE should be less or equal to 0.5 , whereas CR should be more or equivalent to 0.7. As tabulated in Table I, all AVEs values exceeded 0.5 and the CRs are more than 0.7 . The loadings were acceptable with all loadings more than 0.708 (48). Secondly, the structural model for hypotheses testing was carried out. Initially, the discriminant validity using HTMT criteria proposed by preceding research (48) was tested and later improvised by [49]. All HTMT values were $\leq 0.90$, which is deemed acceptable (Table II). It was assumed that all participants realised that all the constructs are distinct. As such, both validity tests indicated that all items were reliable and valid.

Table I Measurement Model

\begin{tabular}{|c|c|c|c|c|}
\hline Constructs & Items & Loadings & A VE & CR \\
\hline WFC & WFC1 & 0.930 & 0.810 & 0.927 \\
\hline & WFC2 & 0.956 & & \\
\hline & WFC3 & 0.806 & & \\
\hline
\end{tabular}




\begin{tabular}{|c|c|c|c|c|}
\hline Constructs & Items & Loadings & A VE & CR \\
\hline FWC & FWC1 & 0.917 & 0.853 & 0.946 \\
\hline & FWC2 & 0.937 & & \\
\hline & FWC3 & 0.915 & & \\
\hline EE & EE1 & 0.805 & 0.631 & 0.923 \\
\hline & EE2 & 0.790 & & \\
\hline & EE3 & 0.722 & & \\
\hline & EE4 & 0.853 & & \\
\hline & EE6 & 0.710 & & \\
\hline & EE8 & 0.812 & & \\
\hline & EE9 & 0.857 & & \\
\hline AC & AC1 & 0.860 & 0.630 & 0.910 \\
\hline & AC2 & 0.848 & & \\
\hline & AC3 & 0.833 & & \\
\hline & AC4 & 0.781 & & \\
\hline & AC5 & 0.723 & & \\
\hline & AC6 & 0.703 & & \\
\hline TI & TI1 & 0.884 & 0.790 & 0.919 \\
\hline & TI4 & 0.927 & & \\
\hline & TI5 & 0.855 & & \\
\hline
\end{tabular}

Note: WFC $=$ Work-Family Conflict, FWC $=$ Family-Work Conflict, $\mathrm{EE}=$ Emotional Exhaustion, $\mathrm{AC}=$ Affective Commitment, $\mathrm{TI}=$ Turnover Intention

Table II Discriminant Validity (HTMT)

\begin{tabular}{|c|c|c|c|c|}
\hline Constructs & $\mathbf{1}$ & $\mathbf{2}$ & $\mathbf{3}$ & $\mathbf{4}$ \\
\hline AC & & & & \\
\hline EE & 0.080 & & & \\
\hline FWC & 0.079 & 0.181 & & \\
\hline TI & 0.561 & 0.084 & 0.118 & \\
\hline WFC & 0.390 & 0.056 & 0.447 & 0.500 \\
\hline
\end{tabular}

\subsection{Structural model}

\subsubsection{Direct effect of WFC and FWC on EE and $T I$}

Firstly, the effect of the four predictors on TI were tested, the $\mathrm{R} 2$ was $0.359(\mathrm{Q} 2=0.259)$ which showed that all the 4 predictors explained $35.9 \%$ of the variance in TI. WFC $(\beta=0.296$, $\mathrm{t}$-value $=3.898$, $\mathrm{p}<0.10)$ and FWC $(\beta=0.450, \mathrm{t}$-value $=5.357, \mathrm{p}<$ 0.10 ) was positively related to TI, thus H1(a) and H1(b) were supported. Similarly, WFC $(\beta=0.808$, tvalue $=8.596, \mathrm{p}<0.10)$ and FWC $(\beta=0.210$, t-value $=3.134, \mathrm{p}<0.10)$ was positively related to EE, thus $\mathrm{H} 2$ (a) and $\mathrm{H} 2$ (b) were also supported.

\subsubsection{Indirect effect of EE between WFC/FWC-TI}

Based on [50], the mediation hypotheses were examined by bootstrapping the indirect effect. There are significant mediating effects that take place if the confidence interval does not straddle a 0. Both WFC $\rightarrow \mathrm{EE} \rightarrow \mathrm{TI}(\beta=0.165, \mathrm{t}-\mathrm{value}=4.231, \mathrm{p}<0.10)$ and FWC $\rightarrow$ EE $\rightarrow$ TI $(\beta=0.188$, t-value $=5.371, \mathrm{p}<$ $0.10)$ were significant. The confidence intervals biascorrected $95 \%$ which also did not show any intervals straddling and thus verifying the findings. Therefore, H3(a) and H3(b) were supported.

\subsubsection{Moderation effect of AC between WFC/FWC-TI}

The moderating effect of affective commitment was examined using the product-indicator approach as suggested in a study [51]. The interaction term between WFC-AC and FWC-AC were created. Before doing this interaction, the variables were mean centred to reduce multicollinearity. When the interaction effect was entered into the model, the $\mathrm{R}^{2}$ increased to 0.359 , giving an $\mathrm{R}^{2}$ change of 15.4 per cent. The interaction effect for WFC*AC was significant $(\beta=0.070$, t-value $=1.842, \mathrm{p}<0.10)$ but not for FWC-AC $(\beta=0.089, \mathrm{t}$-value $=1.046, \mathrm{p}>$ 0.10 ).

The effect size $\mathrm{f}^{2}$ as suggested in a study (52) was 0.240 , which is considered medium. As suggested by research [53], the interaction effect was plotted to see how the moderator changes the relationship between WFC and TI. As hypothesised in H4(a), the results revealed that the positive relationship between WFC and TI are stronger when employees affective commitment is lower. A simple slopes test indicated that WFC was related to TI at both lower and higher levels of affective commitment. In contrast, no significant relationship was found on the interaction between FWC-AC with turnover intentions. Thus, only H4(a) was supported.

\subsection{Discussion}

Findings from the current study contributed new insights into the linkages between work-family interface, emotional exhaustion, and turnover intentions, moderated by affective commitment. WFI, $\mathrm{EE}$, and $\mathrm{AC}$ act as predictors of turnover intentions at the individual level. Under the lens of the JD-R model, WFI among employees is the vital facets of job demands and diminished resources among healthcare personnel like doctors. The findings corroborated with past research, where there is nexus between WFI (WFC/FWC) and TI [9][54][55]. When employees face a high level of pressure, poor work conditions, and imbalance of work and family life, it may create confusion about what behaviour is required [56]. In the medical context, job characteristics like strenuous workload, longer working and shift hours signify a threat in WFI. 
The current findings advocate that WFI stems from overtaxing demand from both work and the family sphere which can jeopardise a medical personnel's well-being, through enhanced emotional exhaustion and eventually leading to the intention to quit. This notion is vital as burnout among medical personnel may threaten the safety and quality of the healthcare services rendered to people. Relevant stakeholders should look into proper planning that highlights on WFI among medical doctors.

Another key result of this study is associated with the moderating effects of AC in relations to WFC-TI but not FWC-TI. The literature suggests that more empirical findings are required to understand ways and means of buffering work stressors. Taris [57] emphasised that only 10 per cent out of 90 research samples examined the buffering impact that showed interaction effects. When conflict between work and family domains are produced, emotional exhaustion will be elevated, hence there is an increased tendency to quit, such that these linkages are weaker when AC is high and stronger when $\mathrm{AC}$ is low.

As suggested by Meyer et al. (25), emotional attachment to the organisation (i.e. a sense of belonging) plays a pivotal role in getting them more resilient to strain when facing high WFC, therefore preventing them from emotional exhaustion and thus, low propensity to leave the job. Following these arguments, affective commitment can be recognised as a protective resource for medical doctors.

\subsection{Conclusion and limitations}

This study provided appealing implications in which an elevated impact on affective commitment and weakening WFI can result in decreased emotional exhaustion and low turnover intentions at the individual level. AC serves as a personal resource in buffering the impact of WFC and EE on TI, which infers that doctors with elevated AC can cope with demands between work and non-work roles conflict, hence reduced intentions to quit their job.

This study is not without its limits. First, the respondents of four public hospitals were mainly medical officers and medical specialists omitting other healthcare professions. Notably, higher involvement from a larger sample and heterogenous professions are recommended. Secondly, no causal effects can be gauged from this study. Future research should utilise the longitudinal and multilevel method to enhance generalisability and examine their changes over time and linkages between AC, WFI, EE, and TI. Future study should consider all the three dimensions of burnout and commitment to seek holistic outcomes in these relationships.

\section{AUTHORS' CONTRIBUTIONS}

IH and RM contributed equally to this paper. IH deliberated on literature review, hypotheses development, data collection and results section. RM contributed to the discussions and limitations section.

\section{ACKNOWLEDGMENTS}

The authors would like to express gratitude to the hospital directors, head of departments and medical doctors who participated in this research from four Malaysian public hospitals.

\section{REFERENCES}

[1] P.W. Hom, T.W. Lee, J.D Shaw, J.P Hausknecht. One hundred years of employee turnover theory and research. J.Appl. Soc. Psychol. 102(3) (2017) 530-45.

[2] ILO. World Social Protection Report 201719: Universal social protection to achieve the Sustainable Development Goals. 2017.

[3] LM. Hung, YS. Lee, DC. Lee. The moderating effects of salary satisfaction and working pressure on the organizational climate, organizational commitment to turnover intention. Int.J.Bus.Soc. 19(1) (2018) 103116.

[4] WB. Schaufeli, TW. Taris, W.Van Rhenen. Workaholism, burnout, and work engagement: Three of a kind or three different kinds of employee well-being? Appl. Psychol. 57(2) (2008) 173-203.

[5] MOH. Health Facts, 2019. Ministry of Health Malaysia, Planning Division Health Informatics Centre. 2019.

[6] UN. World Population Ageing. 2017.

[7] SE Hobfoll. Conservation of Resources: A New Attempt at Conceptualizing Stress. Am Psychol. 44(3) (1989) 513-524.

[8] SE Hobfoll, J Halbesleben, J-PP Neveu, M Westman, SE Hobfol, J Halbesleben, et al. Conservation of resources in the organizational context: The reality of resources and their consequences. Annu. Rev. Organ. Psychol. Organ. Behav. 5(1) (2018) 103-128.

[9] MM Hammond, C Murphy, CA Demsky. Stress mindset and the work-family interface. Int. J. Manpow. 2020. 
[10] AB Bakker, E Demerouti. The Job demandsresources model: State of the art. J. Manag. Psychol. 22(3) (2007) 309-328.

[11] AB Bakker, E Demerouti, AI Sanz-Vergel. Burnout and work engagement: The JD-R approach. Annu. Rev. Organ. Psychol. Organ. Behav. 1(1) (2014) 389-411.

[12] P Voydanoff. Linkages between the workfamily interface and work, family, and individual outcomes: An integrative model. J. Fam. Issues. 23(1) (2002) 138-164.

[13] AM García-Cabrera, AM Lucia-Casademunt, D Cuéllar-Molina, L Padilla-Angulo. Negative work-family/family-work spillover and wellbeing across Europe in the hospitality industry: The role of perceived supervisor support. Tour. Manag. Perspect. (2018) 39-48.

[14] H Kim, Y Kim, DL Kim. Negative workfamily/family-work spillover and demand for flexible work arrangements: the moderating roles of parenthood and gender. Int. J. Hum.Resour. Manag. 30(3) (2019) 361-384.

[15] BM Thompson, A Kirk, DF Brown. Work based support, emotional exhaustion, and spillover of work stress to the family environment: A study of policewomen. Stress Health. 21(3) (2005) 199-207.

[16] AJ Montgomery, E Panagopolou, A Benos. Work-family interference as a mediator between job demands and job burnout among doctors. Stress Health. 22(3) (2006) 203-212.

[17] C Maslach, SE Jackson, MP Leiter. Maslach Burnout Inventory. Maslach Burn Inventory 3rd edn. 1996.

[18] CF Chen, YC Hsu. Taking a closer look at bus driver emotional exhaustion and well-being: evidence from Taiwanese urban bus drivers. Saf. Health Work. 11(3) (2020) 353-360.

[19] E Kemp, SW Kopp, EC Kemp. Take this job and shove it: Examining the influence of role stressors and emotional exhaustion on organizational commitment and identification in professional truck drivers. J. Bus. Logist. 34(1) (2013) 33-45.

[20] JN Scanlan, M Still. Relationships between burnout, turnover intention, job satisfaction, job demands and job resources for mental health personnel in an Australian mental health service. BMC Health Serv. Res. 19(1) (2019) 1-11.

[21] TA Wright, Cropanzano R. Emotional exhaustion as a predictor of job performance and voluntary turnover. J. Appl. Psychol. 83(3) (1998) 486-493.
[22] O Hämmig. Explaining burnout and the intention to leave the profession among health professionals - A cross-sectional study in a hospital setting in Switzerland. BMC Health Serv. Res. 18(1) (2018) 1-11.

[23] SS McLinton, MY Loh, MF Dollard, MMR Tuckey, MA Idris, S.Morton. Benchmarking working conditions for health and safety in the frontline healthcare industry: Perspectives from Australia and Malaysia. J. Adv. Nurs. 74(8) (2018) 1851-1862.

[24] JY Huynh, D Xanthopoulou, AH Winefield. The job demands-resources model in emergency service volunteers: Examining the mediating roles of exhaustion, work engagement and organizational connectedness. Work Stress. 28(3) (2014) 305-322.

[25] JP Meyer, DJ Stanley, L Herscovitch, L Topolnytsky. Affective, continuance, and normative commitment to the organization: A meta-analysis of antecedents, correlates, and consequences. J Vocat Behav. 61(1) (2002) 20-52.

[26] K Skagert, L Dellve, G Ahlborg. A prospective study of managers' turnover and health in a healthcare organization. J. Nurs. Manag. 20(7) (2012) 889-899.

[27] R V Mahto., G Vora, WC McDowell, D Khanin. Family member commitment, the opportunity costs of staying, and turnover intentions. J. Bus. Res. 108 (2020) 9-19.

[28] RW Griffeth, PW Hom, Gaertner S. A metaanalysis of antecedents and correlates of employee turnover: Update, moderator tests, and research implications for the next millennium. J. Manag. 26(3) (2000) 463-488.

[29] RP Tett, JP Meyer. Job satisfaction, organizational commitment, turnover intention, and turnover: Path analyses based on meta-analytic findings. Perspect. Psychol. 46(2) (1993) 259-293.

[30] Z Hassan, MF Dollard, AH Winefield. Workfamily conflict in East vs western countries. Cross Cult. Manag. 17(1) (2010) 30-49.

[31] T.D Allen, DE Herst, CS Bruck, Sutton M. Consequences associated with work-to-family conflict: a review and agenda for future research. J. Occup. Health Psychol. 5(2) (2000) 278-308.

[32] EA Pope. Work-family and family-work conflict as a function of role commitment and core self-evaluation. 2019

[33] S Zhou, X Li, B Gao. Family/friends support, work-family conflict, organizational 
commitment, and turnover intention in young preschool teachers in China: A serial mediation model. Child Youth Serv. Rev. 2020104997

[34] AM Dåderman, BA Basinska. Job demands, engagement, and turnover intentions in Polish nurses: The role of work-family interface. Front. Psychol. (2016) 1-14.

[35] MN Turliuc, D Buliga. Job and family satisfaction and work-family enhancement. Mediating processes. Procedia Soc. Behav. Sci. 59 (2015) 115-159.

[36] M Westman, D Etzion, E Gortler. The workfamily interface and burnout. Int. J. Stress. Manag. 11(4) (2004) 413-428.

[37] HK Knudsen, LJ Ducharme, PM Roman. Turnover intention and emotional exhaustion "at the top": adapting the job demandsresources model to leaders of addiction treatment organizations. J Occup. Health Psychol. 14(1) (2009) 84-95.

[38] C Nohe, K Sonntag. Work-family conflict, social support, and turnover intentions: A longitudinal study. J. Vocat. Behav. 85(1) (2014) $1-12$.

[39] M Galletta, I Portoghese, P Melis, CIA Gonzalez, G Finco, D'Aloja E, et al. The role of collective affective commitment in the relationship between work-family conflict and emotional exhaustion among nurses: A multilevel modeling approach. BMC Nurs. 18(1) (2019) 1-9.

[40] RA Matthews, LM Kath, JL Barnes-Farrell. A short, valid, predictive measure of workfamily conflict: item selection and scale validation. J Occup. Health Psychol. 15(1) (2010) 75-90.

[41] NJ Allen, JP Meyer. The measurement and antecedents of affective, continuance and normative commitment to the organization. J. Occup Psychol. 63 (1990) 1-18.

[42] CFC Bothma, G Roodt. The validation of the CFC turnover intention scale. SA J. Hum Resour. Manag. 11(1) (2013) 1-12.

[43] CM Ringle, M Sarstedt, R Mitchell, Gudergan SP. Partial least squares structural equation modeling in HRM research. Int. J. Hum. Resour. Manag. 31(12) (2020) 1617-1643.

[44] WW Chin, BL Marcolin, PR Newsted. A Partial least squares latent variable modeling approach for measuring interaction effects:
Results from a Monte Carlo Simulation Study and an Electronic-Mail Emotion/Adoption Study. Inf. Syst. Res. 14(2) (2003) 189-217.

[45] N Kock, GS Lynn. Lateral collinearity and misleading results in variance-based SEM: An illustration and recommendations. J. Assoc. Inf. Syst. 13(7) (2012) 546-580.

[46] JC Anderson, DW Gerbing. Structural equation modeling in practice: A review and recommended two-step approach. Psychol. Bull. 103(3) (1988) 411-423.

[47] JF Hair, JJ Risher, M Sarstedt, CM Ringle. When to use and how to report the results of PLS-SEM. Eur. Bus. Rev. 31(1) (2019) 2-24.

[48] J Henseler, CM Ringle, M Sarstedt. A new criterion for assessing discriminant validity in variance-based structural equation modeling. Acad. Mark. Sci. Rev. 43(1) (2014) 115-135.

[49] M Sarstedt, JF Hair, JH Cheah, JM Becker, Ringle CM. How to specify, estimate, and validate higher-order constructs in PLS-SEM. Australas. Mark. J. 27(3) (2019) 197-211.

[50] KJ Preacher, MJ Zyphur, Z Zhang. A general multilevel SEM framework for assessing multilevel mediation. Psychol. Methods. 15(3) (2010) 209-233.

[51] G Fassott, J Henseler, PS Coelho. Testing moderating effects in PLS path models with composite variables. Ind. Manage. Data Syst. 16(9) (2016) 1887-1900.

[52] J Cohen. Statistical power analysis for the behavioral sciences. $2^{\text {nd }}$ edn. Lawrence Erlbaum Associates. 1988. 567.

[53] VDawson. Moderation in management research: What, why, when, and how. J. Bus. Psychol. 29(1) (2014) 1-19.

[54] OM Karatepe, G Karadas. The effect of psychological capital on conflicts in the workfamily interface, turnover and absence intentions. Int. J. Hosp. Manag. 43 (2014) 132-143.

[55] B Rajkonwar, M Rastogi. The Impact of Work-Family Issues on Turnover Intentions among Nurses? A Study from North-eastern India. J. Health Manag. 20(2) (2018) 164-177.

[56] MJ Sirgy, DJ Lee. Work-life balance: An integrative review. Appl. Res. Qual. Life. 13(1) (2018) 229-254.

[57] TW Taris. Bricks without clay: On urban myths in occupational health psychology. Work Stress. 2006;20(2):99-104. 